\title{
Excited-state proton transfer of 4-hydroxyl-1, 8-naphthalimide derivatives: A combined experimental and theoretical investigation
}

Zongjin Qu, Peng Li, Xuexiang Zhang, Endong Wang, Yanni Wang, Panwang Zhou*

State Key Laboratory of Molecular Reaction Dynamics, Dalian Institute of Chemical Physics (DICP), Chinese Academy of Sciences (CAS), Dalian, P. R. China

E-mail: pwzhou@dicp.ac.cn

Tel: +86-411-84379293; Fax: +86-411-84675584

\begin{abstract}
The photophysical properties of N-butyl-4-hydroxyl-1, 8-naphthalimide (BOH) and $\mathrm{N}$-(morpholinoethyl)-4-hydroxy-1, 8-naphthalimide (MOH) in various solvents are presented and the density functional theory (DFT) / time-dependent density functional theory (TDDFT) methods at the B3LYP/TZVP theoretical level are adopted to investigate the UV-visible absorption and emission data. An efficient intermolecular excited-state proton transfer (ESPT) reaction occurs for both compounds in DMSO, methanol and water. In aqueous solution, both $\mathrm{BOH}$ and $\mathrm{MOH}$ can be used as ratiometric $\mathrm{pH}$ probes and perform as strong photoacids with $\mathrm{pKa}^{*}=-2.2,-2.4$, respectively. Most interestingly, in the steady-state fluorescence spectra of $\mathrm{BOH}$ and $\mathrm{MOH}$ in concentrated $\mathrm{HCl}$, an unexpected blue-shifted band is observed and assumed to originate from the contact ion pair (CIP) formed by hydronium ion and the anionic form of the photoacid resulted from ESPT. Theoretical calculations are used to simulate the CIP in the case of $\mathrm{BOH}$, which afford reasonable results compared with the experimental data.
\end{abstract}

\section{Keywords:}

Naphthalimide

Excited-state proton transfer

Photoacid

Contact ion pair

Time-dependent density functional theory

\section{Introduction}

Upon photoexcitation, aromatic alcohols $(\mathrm{ROH})$ such as naphthols, hydroxyquinolines, and hydroxypyrenes may increase the acidity dramatically. Research on this photoinduced deprotonation is first described by Förster in 1949 [1] and still attracting intensive attention in the field of biology and physical chemistry [2-11]. The Eigen-Weller model for proton transfer is used to depict this process, where the initial short-range proton transfer forms a contact ion pair (CIP) as a reaction intermediate followed by diffusion controlled separation of the ions [12-13].

1

(C) 2016. This manuscript version is made available under the Elsevier user license http://www.elsevier.com/open-access/userlicense/1.0/ 
Recently, Brouwer and coworkers synthesized and characterized some hydroxy-substituted 1, 8-naphthalimide derived "super" photoacids, where the hydroxyl group is located at the 3 or 6 position of the naphthalimide ring [6, 14]. However, for 4-hydroxyl-1, 8-naphthalimide derivatives, which are extensively used for designing turn-on or rationmetric fluorescent indicators for bioimaging [15-29], the photophysical properties and the excited-state proton transfer (ESPT) reactions are rarely studied [30].

In this contribution, the steady-state absorption and emission spectra of two 4-hydroxyl-1, 8-naphthalimide derivatives $(\mathrm{BOH}$ and $\mathrm{MOH}$, Scheme 1) in organic solvents and water with various $\mathrm{pH}$ values are recorded. The density functional theory (DFT) / time-dependent density functional theory (TDDFT) methods at B3LYP/TZVP theoretical level are adopted to investigate the UV-visible absorption and emission data. In the study of the ESPT of 5-cyano-2-naphthol in sub- and supercritical water, Kobayashi and coworkers [31] found that the band of their excited neutral $\left(\mathrm{ROH}^{*}\right)$ and anionic $\left(\mathrm{RO}^{-*}\right)$ species were replaced by a single band of unknown $\mathrm{X}^{*}$ in the steady-state fluorescence spectra; they assigned the fluorescence of their unknown chemical species as CIP; however, their attempts of using theoretical calculations to gain a stable structure as the direct evidence for the existence of the CIP failed. In this paper, we present the observation of an unexpected blue shifted single band in the fluorescence spectra of $\mathrm{BOH}$ and $\mathrm{MOH}$ in concentrated $\mathrm{HCl}$, which is distinct from the fluorescence of the neutral or anionic species and is assumed to emit from the CIP resulted from the ESPT reaction. Meanwhile, the DFT/TDDFT methods were used to gain more insight into the CIP formed by $\mathrm{BO}^{-*}$ and hydrated proton. The calculated absorption and fluorescence peaks were used to test the proposed CIP models by comparing with our experimental data. The structural changes of the hydrogen-bonded complexes from the ground-state $\left(\mathrm{S}_{0}\right)$ to the first excited-state $\left(\mathrm{S}_{1}\right)$ and the potential curves of the ESPT reaction along the hydrogen-bond coordinate are also discussed.

Scheme 1 Chemical structures of $\mathrm{BOH}$ and $\mathrm{MOH}$

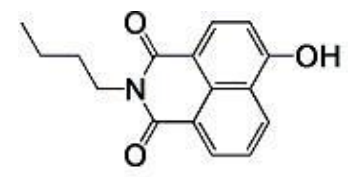

$\mathrm{BOH}$

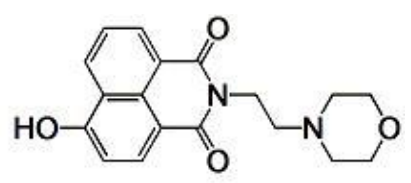

$\mathrm{MOH}$

\section{Experimental section}

\subsection{Instruments and Materials}

Steady-state UV-visible absorption spectra were measured on a Lambda 35 UV-visible Spectrophotometer (Perkin-Elmer) with matched 10-mm quartz cuvettes. Fluorescence spectra were obtained from Fluoromax-4 Spectrofluorometer (Horiba-Jobin Yvon, monochromator calibrated). Except for the samples in $\mathrm{H}_{2} \mathrm{SO}_{4}$ aqueous solutions $\left(17 \pm 1^{\circ} \mathrm{C}\right)$, all the other experiments were performed at room temperature $\left(26 \pm 1^{\circ} \mathrm{C}\right)$.

Acetonitrile, toluene, dimethylsulfoxide (DMSO), dichloromethane (DCM) and methanol were purchased from reputable suppliers and used as received (HPLC grade). Ultrapure water (resistivity 
18.2 $\mathrm{M} \Omega \cdot \mathrm{cm}$ ) from a Millipore water purification system was used throughout. All the solvents were checked for fluorescent impurities prior to use. Other chemicals were of analytical grade without further purification. Phosphate buffer $(50 \mathrm{mM})$ with various $\mathrm{pH}$ values were prepared by mixing the aqueous solutions of monosodium phosphate $(50 \mathrm{mM})$, sodium hydrogen phosphate $(50 \mathrm{mM})$ or phosphoric acid $(50 \mathrm{mM})$, measured with an Ohaus $\mathrm{pH}$ meter STARTER2100. Phosphate buffer saline (PBS) was aqueous solution of phosphate $(10 \mathrm{mM}), \mathrm{NaCl}(8.0 \mathrm{~g} / \mathrm{L})$ and $\mathrm{KCl}(0.2 \mathrm{~g} / \mathrm{L}), \mathrm{pH}$ 7.3. Spectra in phosphate or $\mathrm{HCl}$ aqueous solutions were collected from samples of $\mathrm{BOH}$ and $\mathrm{MOH}$ diluted from their DMSO stock solutions.

The 4-hydroxyl-1, 8-naphthalimide derivatives ( $\mathrm{BOH}$ and $\mathrm{MOH}$ ) were synthesized following procedures described in the literatures [17, 22]. NMR and mass spectra were recorded to characterize the compounds. For BOH: ${ }^{1} \mathrm{H}$ NMR (500 MHz, d $\left.{ }^{6}-\mathrm{DMSO}\right) \delta(\mathrm{ppm}): 11.84(\mathrm{~s}, 1 \mathrm{H}), 8.50$ (dd, $J=8.5$ $\mathrm{Hz}, 1 \mathrm{H}), 8.43(\mathrm{dd}, J=7.0 \mathrm{~Hz}, 1 \mathrm{H}), 8.33(\mathrm{~d}, J=8.0 \mathrm{~Hz}, 1 \mathrm{H}), 7.73(\mathrm{t}, J=7.8 \mathrm{~Hz}, 1 \mathrm{H}), 7.14(\mathrm{~d}, J=8.0$ $\mathrm{Hz}, 1 \mathrm{H}), 4.01$ (t, $J=7.5 \mathrm{~Hz}, 2 \mathrm{H}), 1.63-1.57$ (m, $2 \mathrm{H}), 1.39-1.32(\mathrm{~m}, 2 \mathrm{H}), 0.94(\mathrm{t}, J=7.5 \mathrm{~Hz}, 3 \mathrm{H}) .{ }^{13} \mathrm{C}$ NMR (126 MHz, d ${ }^{6}$-DMSO) $\delta$ (ppm): 13.63, 19.76, 29.69, 39.02, 109.85, 112.56, 121.71, 122.29, 125.41, 128.73, 129.07, 130.95, 133.37, 160.13, 162.89, 163.56. MS (API-ES): m/z, Calcd for $\mathrm{C}_{16} \mathrm{H}_{15} \mathrm{NO}_{3}$ : 269.11, found: [M-H] 268.16 . For MOH: ${ }^{1} \mathrm{H}$ NMR （400 MHz, d $\mathrm{d}^{6}-\mathrm{DMSO} ） \delta(\mathrm{ppm}): 8.53$ $(\mathrm{dd}, 1 \mathrm{H}, \mathrm{J}=8.2 \mathrm{~Hz}), 8.46(\mathrm{dd}, 1 \mathrm{H}, \mathrm{J}=7.2 \mathrm{~Hz}), 8.35(\mathrm{~d}, \mathrm{~J}=8.4 \mathrm{~Hz}, 1 \mathrm{H}), 7.77-7.73(\mathrm{~m}, 1 \mathrm{H}), 7.13(\mathrm{~d}, 1 \mathrm{H}, \mathrm{J}=8.0$ $\mathrm{Hz}), 4.17(\mathrm{t}, 2 \mathrm{H}, \mathrm{J}=7.0 \mathrm{~Hz}), 3.55(\mathrm{t}, 4 \mathrm{H}, \mathrm{J}=4.6 \mathrm{~Hz}), 2.60-2.50(\mathrm{~m}, 6 \mathrm{H}) \cdot{ }^{13} \mathrm{C}$ NMR (d $\left.{ }^{6}-\mathrm{DMSO}, 100 \mathrm{MHz}\right)$ $\delta(\mathrm{ppm}): 164.20,163.47,161.26,134.13,131.61,129.77,129.48,125.96,123.02,122.21,112.65$, 110.57, 66.58, 56.12, 53,82, 36.91. HRMS (ESI) Calcd for $\mathrm{C}_{18} \mathrm{H}_{19} \mathrm{~N}_{2} \mathrm{O}_{4}\left[\mathrm{MH}^{+}\right]$327.1345, found 327.1358 .

\subsection{Theoretical calculation details}

DFT and TDDFT methods were used to do theoretical simulations in this work with Gaussian09 programs [32]. The Becke's three-parameter hybrid exchange functional with a Lee-Yang-Parr gradient-corrected correlation (B3LYP) [33] was used as a method of choice. The triple- $\zeta$ valence quality with one set of polarization functions (TZVP) basis sets [34] were used in all the calculations. Environmental effects (here, water or acetonitrile, as in the experiment) were accounted for using the IEFPCM solvation model. The vertical excitation and emission energies are based on the optimized geometries with no constraints to all the atoms, bonds, angles or dihedral angles during the optimizations. Vibrational frequencies are analyzed to confirm the validity of the stationary points.

\section{Results and discussion}

\subsection{Spectra in organic solvents}

Emission spectra of $\mathrm{BOH}$ and $\mathrm{MOH}$ in several organic solvents are presented in Fig. 1. There is only one fluorescence band emitted by $\mathrm{ROH}^{*}$ in $\mathrm{DCM}$, toluene or acetonitrile, while in DMSO or methanol, two fluorescence bands which are assigned to $\mathrm{ROH}^{*}$ and $\mathrm{RO}^{-*}$ are monitored. In DMSO or methanol, the absorption spectra indicate that both $\mathrm{RO}^{-}$and $\mathrm{ROH}$ exist in the ground-state (Fig. S1, S2) In the presence of $\mathrm{HCl}(12 \mathrm{mM})$ in DMSO or methanol, the compounds predominately exist as the neutral forms in the ground state; however, there are still two emission bands in the spectra of those solutions (Fig. S3). Thus, it is evident that $\mathrm{BOH}$ and $\mathrm{MOH}$ undergo ESPT reactions efficiently in DMSO or methanol, but not in DCM, toluene or acetonitrile. 

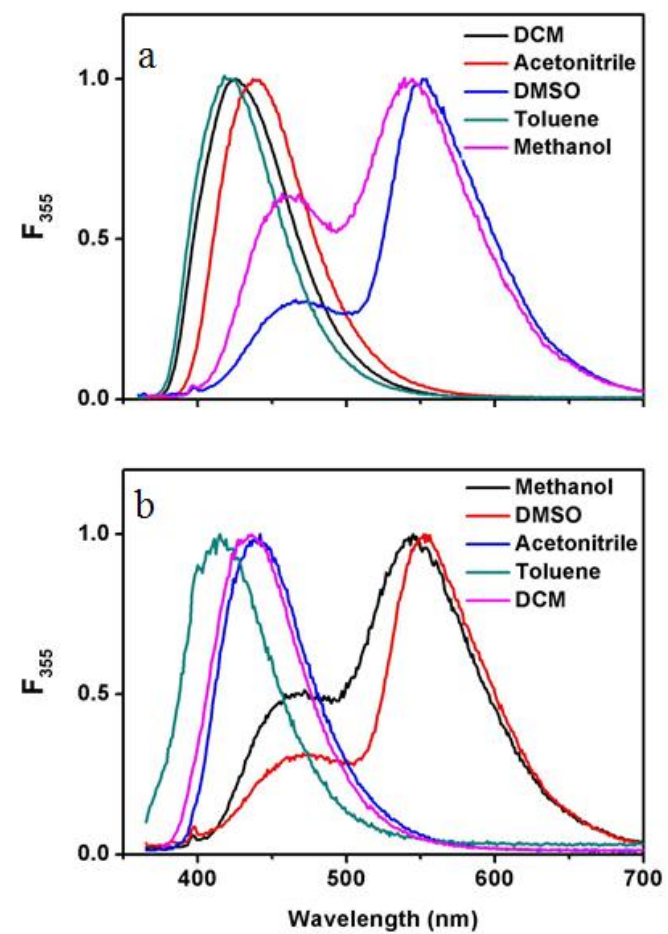

Fig. 1. Normalized fluorescence spectra of (a) $\mathrm{BOH}$ and (b) $\mathrm{MOH}$ in organic solvents (the excitation wavelength, $\lambda_{e x}=355 \mathrm{~nm}$ ). The concentrations of these solutions are $10^{-6} \sim 10^{-5} \mathrm{M}$.

The absorption and fluorescence spectral properties of the two compounds in the above solvents, including the absorption and fluorescence maxima $\left(\lambda_{a}, \lambda_{f}\right)$, the fluorescence quantum yield $\left(\Phi_{f}\right)$ values, are summarized in Table 1. The absorption maxima for samples in DMSO and methanol, where both the neutral and anionic forms exist, are determined by spectral decomposition with a sum of two gaussians. As for the emission data, we noted that Brouwer and coworkers reported the requirement of three rather than two gaussians to fit the fluorescence spectrum of EG-dHONI in DMSO [6]; in our case, a sum of three gaussians was required to fit the curves for samples in DMSO and methanol (Fig. S4), since two gaussians were not adequate to model the spectra (Fig. S5).

Table 1

Photophysical properties of $\mathrm{BOH}$ and $\mathrm{MOH}$ in organic solvents

\begin{tabular}{cccccccc}
\hline \multirow{2}{*}{ Solvent } & \multicolumn{3}{c}{ BOH } & & \multicolumn{3}{c}{ MOH } \\
\cline { 2 - 4 } \cline { 6 - 8 } & $\lambda_{d} / \mathrm{nm}$ & $\lambda_{f} / \mathrm{nm}$ & $\Phi_{f}{ }^{a}$ & & $\lambda_{d} / \mathrm{nm}$ & $\lambda_{f} / \mathrm{nm}$ & $\Phi_{f}{ }^{a}$ \\
\hline Toluene & 360 & 420 & 0.97 & & 361 & 415 & 0.040 \\
DCM & 360 & 425 & 1.0 & & 363 & 436 & 0.033 \\
Acetonitrile & 365 & 440 & 0.78 & & 365 & 442 & 0.053 \\
DMSO & $376^{\mathrm{b}}, 483^{\mathrm{c}}$ & 467,550 & 0.02 & & $376^{\mathrm{b}}, 483^{\mathrm{c}}$ & 470,552 & 0.15 \\
Methanol & $378^{\mathrm{b}}, 453^{\mathrm{c}}$ & 460,543 & 0.082 & & $378^{\mathrm{b}}, 453^{\mathrm{c}}$ & 467,545 & 0.056 \\
\hline
\end{tabular}

${ }^{\mathrm{a}} \Phi_{f}$ values are determined by referring to sulfate quinine in $0.05 \mathrm{M} \mathrm{H}_{2} \mathrm{SO}_{4}\left(\Phi_{f}=0.55\right)$ [35]. The confidence is $\pm 10 \%$. 
${ }^{\mathrm{b}, \mathrm{c}}$ Data of the neutral and anionic forms determined by decomposition of the absorption spectra with a sum of two gaussians.

In contrast to $\mathrm{BOH}$, the $\Phi_{f}$ values of $\mathrm{MOH}$ in aprotonic solvents such as toluene, DCM or acetonitrile are substantially small. To investigate this effect of substitution, theoretical calculations were carried out by using the Gaussian 09 program with acetonitrile as a representative solvent (Table 2). It is revealed that the fluorescence of $\mathrm{MOH}$ is quenched by photoinduced electron transfer (PET) from the morpholine group to the naphthalimide ring, whereas no PET happens in the case of $\mathrm{BOH}$. The calculated absorption peaks for $\mathrm{MOH}$ and $\mathrm{BOH}$ are in good agreement with the experimental data. Obviously, the highest occupied molecular orbital (HOMO) of $\mathrm{MOH}$ is located at the morpholine group while the lowest unoccupied molecular orbital (LUMO) is located at the naphthalimide ring; the small oscillator strength $(f=0.0011)$ of $S_{0} \rightarrow S_{1}$ implies a forbidden electronic transition, indicating that the $\mathrm{S}_{1}$ state of $\mathrm{MOH}$ is a dark state rather than an emissive state. Absence of the morpholine group for $\mathrm{BOH}$ makes the transition $\mathrm{S}_{0} \rightarrow \mathrm{S}_{1}$ allowed $(f=0.2659)$. The satisfactory agreement between the experimental and calculation results indicates that the DFT/TDDFT methods used here is suitable for the investigation.

Table 2

Calculated properties of electronically excited states by TDDFT/B3LYP/TZVP, based on the optimized $\mathrm{S}_{0}$ state geometries of $\mathrm{MOH}$ and $\mathrm{BOH}$ with acetonitrile as a solvent.

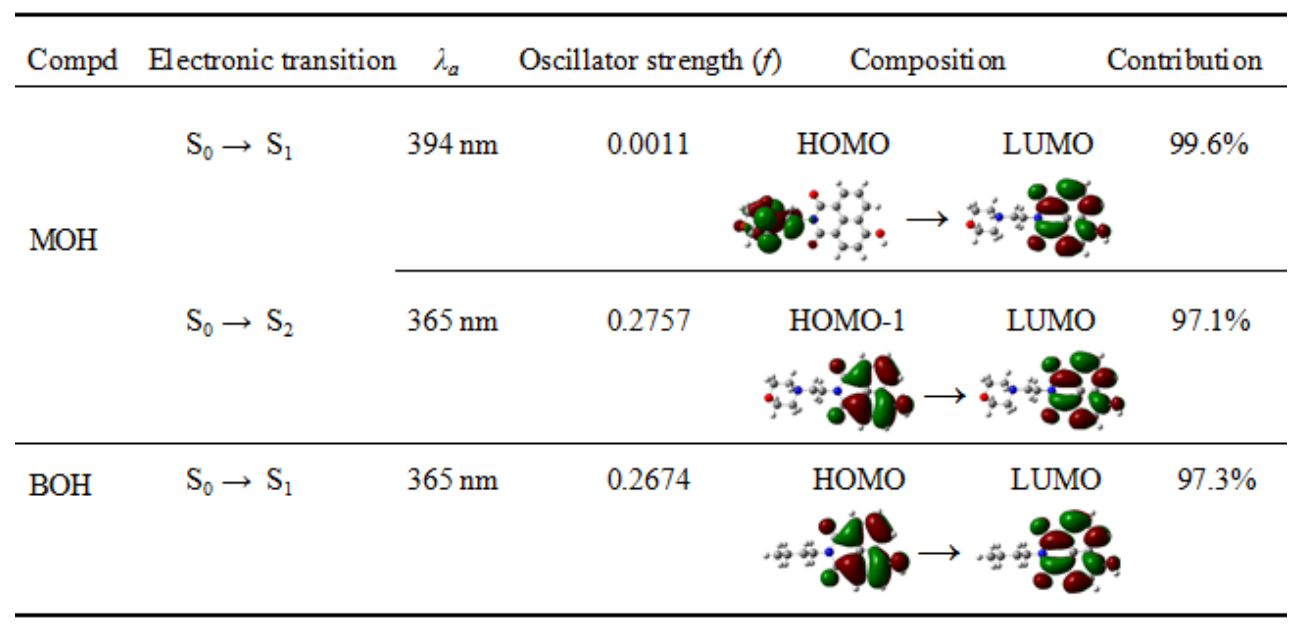

\subsection{Spectra in phosphate buffer}

Next, we investigated the ESPT reactions in water. As shown in Fig. 2a, with pH decrease, the absorption spectra of $\mathrm{BOH}$ change continuously with an isosbestic point at ca. $405 \mathrm{~nm}$, reflecting the steady-state protolytic equilibria. The $\mathrm{pKa}$ value of $\mathrm{BOH}$ is determined to be 5.8 by referring to the Henderson-Hasselbach-type mass action equation. MOH undergoes similar absorption changes and exhibits a pKa of 5.3 (Fig. 2b). 

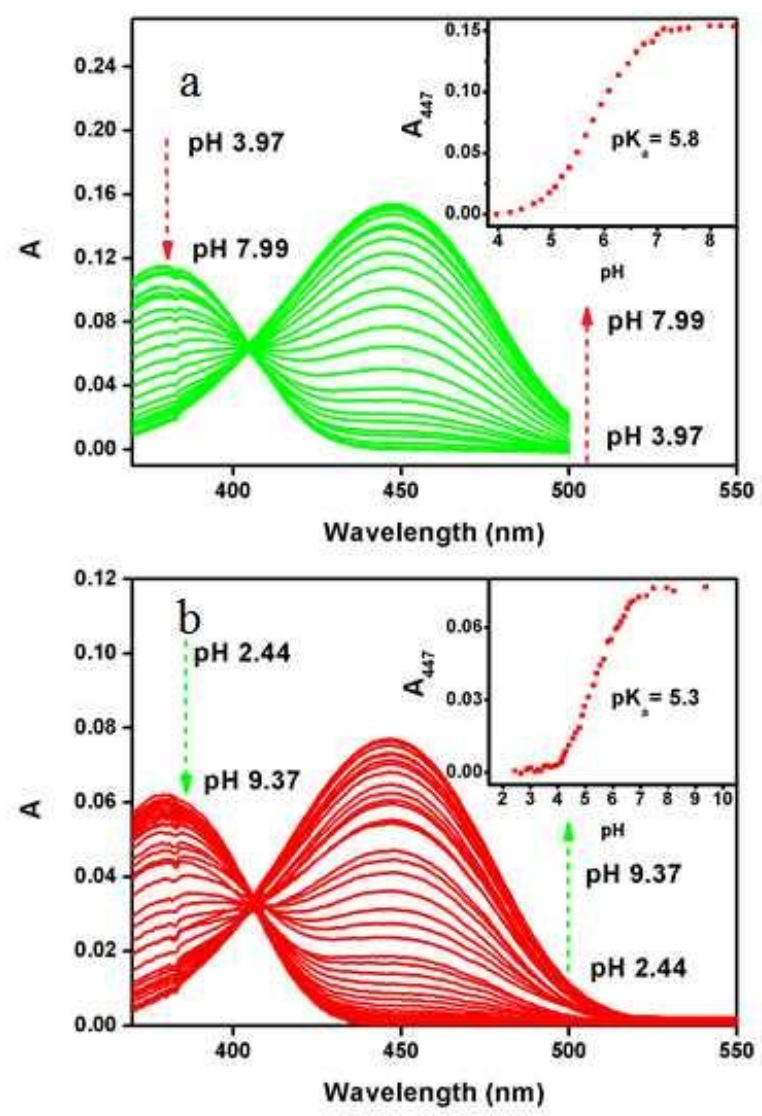

Fig. 2. Absorption spectra of (a) $\mathrm{BOH}(13 \mu \mathrm{M})$ and (b) $\mathrm{MOH}(5 \mu \mathrm{M})$ at various $\mathrm{pH}$ values in aqueous solution. The inset graphs show the absorption at $447 \mathrm{~nm}\left(A_{447}\right)$ as a function of $\mathrm{pH}$ values. The experiment was conducted in phosphate buffer $(50 \mathrm{mM})$ with $1 \%$ DMSO as a co-solvent.

The fluorescence emission and excitation spectra of BOH were obtained. As shown in Fig. 3a, unlike the appearance of two emission bands in DMSO or methanol, BOH shows only one fluorescence band peaked at ca. $548 \mathrm{~nm}$ in aqueous solutions ( $\mathrm{pH} 2.58 \sim 10.55)$. Calculated by TDDFT/B3LYP/TZVP, the fluorescence peaks of $\mathrm{BOH}^{*}$ and $\mathrm{BO}^{-*}$ in water are predicted to be $428 \mathrm{~nm}(\mathrm{f}=0.2208)$ and 540 $\mathrm{nm}(\mathrm{f}=0.2208)$, respectively. Thus the $548 \mathrm{~nm}$ fluorescence must come from $\mathrm{BO}^{-*}$. Since the neutral form of $\mathrm{BOH}$ dominates at $\mathrm{pH}$ bellow 4.0 in the ground-state (Fig. 2a), it is crystal clear that at pH 2.58 the $548 \mathrm{~nm}$ fluorescence is emitted by $\mathrm{BO}^{-*}$ resulted from an ESPT process. Due to this ESPT process and the steady-state protolytic equilibria, we can see in the excitation spectra (Fig. 2b) that, as the $\mathrm{pH}$ value increases in the range of 1.85-10.55, the fluorescence intensity at $550 \mathrm{~nm}$ decreases progressively with $\lambda_{e x}=375 \mathrm{~nm}$ and increases steadily with $\lambda_{e x}=445 \mathrm{~nm}$. In the $\mathrm{pH}$ range of $5.65-7.43$, there is a linear relationship between $\mathrm{pH}$ values and the $445 / 375-\mathrm{nm}$ excitation ratios $\left(F_{445}^{550} / F_{375}^{550}\right)$ with a linear coefficient $\left(\mathrm{R}^{2}\right)$ 0.9921. Fig. 3a shows that the emission spectra of $\mathrm{BOH}$ is $\mathrm{pH}$ sensitive; however, under the excitation light around $405 \mathrm{~nm}$, the fluorescence intensity at $550 \mathrm{~nm}$ is rather stable even though pH changes. What's more, the $405 \mathrm{~nm}$ semiconductor laser is usually available for a confocal laser scanning microscopy (CLSM). Thus, for fluorescent probes based on the 4-hydroxyl-1, 
8-naphthalimide derivatives, it may be helpful to diminish the effect of $\mathrm{pH}$ with the choice of the 405 $\mathrm{nm}$ laser as the light source during imaging with CLSM.
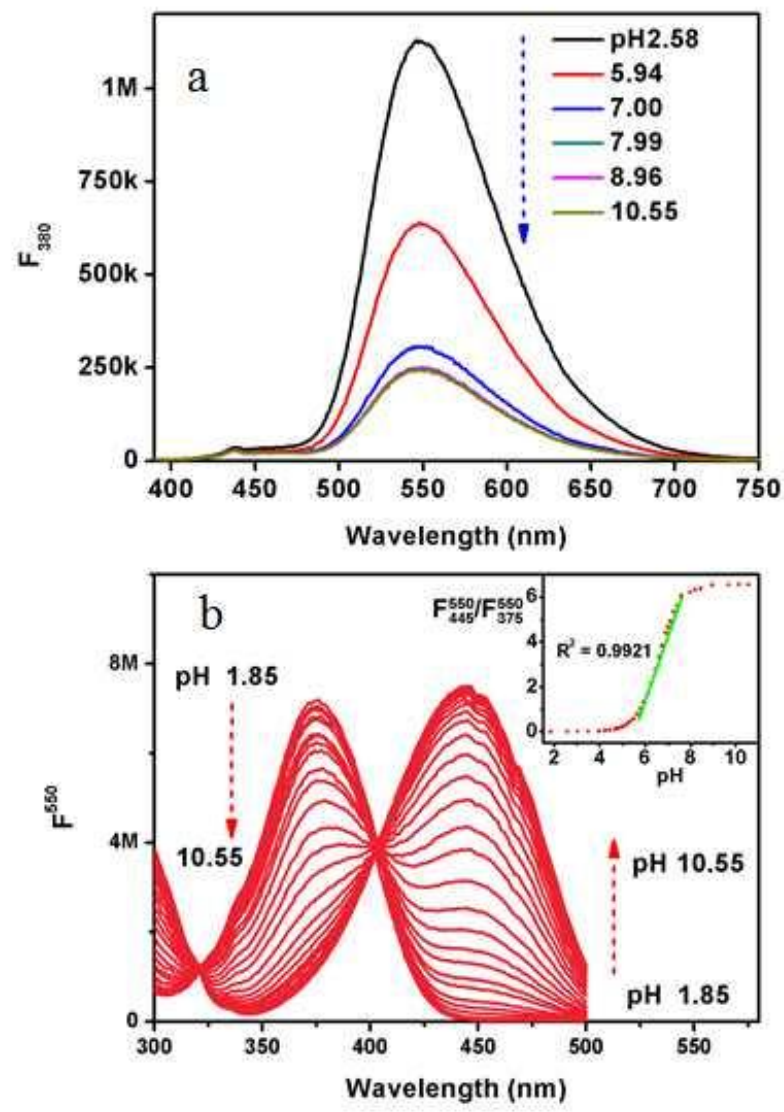

Fig. 3. (a) Fluorescence emission spectra of $\mathrm{BOH}(13 \mu \mathrm{M})$ at various $\mathrm{pH}$ values, $\lambda_{e x}=380 \mathrm{~nm}$. Note that the $438 \mathrm{~nm}$ peak is due to the Raman scattering. (b) The excitation spectra of $\mathrm{BOH}(13 \mu \mathrm{M})$ at various $\mathrm{pH}$ values, $\lambda_{e m}=550 \mathrm{~nm}$. The inset shows the $\mathrm{pH}$ titration curve of $F_{445}^{550} / F_{375}^{550}$. The experiment was conducted in phosphate buffer $(50 \mathrm{mM})$ with $1 \%$ DMSO as a co-solvent.

Interestingly, the fluorescence peak of $\mathrm{MOH}$ in phosphate buffer shifted smoothly from $548 \mathrm{~nm}$ at pH 9.37 to $553 \mathrm{~nm}$ at pH 1.89 under the $380 \mathrm{~nm}$ excitation light (Fig. 4a). This shift is not observed in the case of $\mathrm{BOH}$, thus it should be attribute to the morpholine group of $\mathrm{MOH}$. The anionic and zwitterionic forms of $\mathrm{MOH}$ are calculated to emit at $540 \mathrm{~nm}(\mathrm{f}=0.2211)$ and $542 \mathrm{~nm}(\mathrm{f}=0.2192)$ respectively. Therefore, it is proposed that the slight red-shift of the fluorescence band is contributed by the protonation of the nitrogen atom of the morpholine group. Due to this shift, in the $\mathrm{pH}$ range of 4.5-7.0, there is a linear relationship between $\mathrm{pH}$ and the 560/500-nm emission ratio, $F_{380}^{560} / F_{380}^{500}$ (Fig. 4a, inset). Meantime, there is also a linear relationship for $\mathrm{MOH}$ between the excitation ratios and $\mathrm{pH}$ values in the range of 5.29 7.47 (Fig. 4b). 

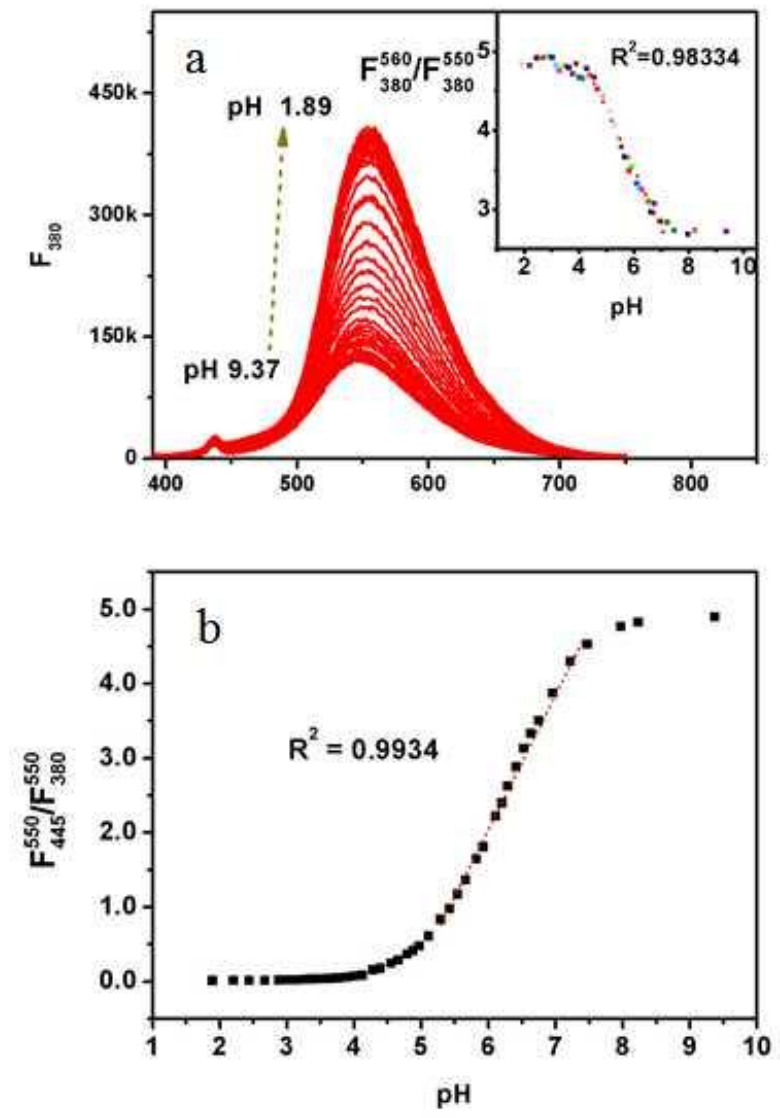

Fig. 4. (a) Fluorescence spectra of $\mathrm{MOH}(5 \mu \mathrm{M})$ at various $\mathrm{pH}$ values, $\lambda_{e x}=380 \mathrm{~nm}$. The inset shows the $\mathrm{pH}$ titration curve of $F_{380}^{560} / F_{380}^{500}$. (b) The $\mathrm{pH}$ titration curve of $F_{445}^{550} / F_{380}^{550}$ in the aqueous solution of $\mathrm{MOH}(5 \mu \mathrm{M})$, phosphate buffer $(50 \mathrm{mM})$ with $1 \%$ DMSO as a co-solvent.

By referring to N-butyl-4-butylamino-1, 8-naphthalimide in absolute alcohol $\left(\Phi_{f}=0.81\right)$ [36], the $\Phi_{f}$ values of $\mathrm{BOH}$ and $\mathrm{MOH}$ in phosphate buffer saline (PBS, $\mathrm{pH} 7.3$ ) were determined to be 0.053 and 0.075 , respectively. The $\Phi_{f}$ values are higher than those of the 1,8-naphthalimide derived "super" photoacids reported in ref. 6 in water $(<0.005$ in all cases) and comparable to some published $\mathrm{pH}$ fluorescent probes [37]. Thus, $\mathrm{BOH}$ and $\mathrm{MOH}$ could be used as dual-excitation ratiometric fluorescent probes allowing the measurement of the fluorescence intensity at two excitation wavelengths.

\subsection{Spectra in aqueous solutions of $\mathrm{HCl}$}

To get results at lower $\mathrm{pH}$, the fluorescence spectra of the 4-hydroxyl-1, 8-naphthalimide s were then investigated in aqueous solutions of $\mathrm{HCl}$. As shown in Fig. 5, the emission from $\mathrm{BO}^{-*}$ and $\mathrm{MO}^{-*}$ is depressed and broadened by $\mathrm{H}^{+}$, probably via the adiabatic recombination between proton and $\mathrm{RO}^{-*}$ [11]; meantime, the neutral emission keeps very weak and grows with the increase of $\mathrm{HCl}$. By spectral decomposition, the neutral peaks are obtained as $458 \mathrm{~nm}$ and $464 \mathrm{~nm}$, respectively (Fig. S6). The emission maxima of the anionic forms in water are determined as $548 \mathrm{~nm}$ and $553 \mathrm{~nm}$ from the smoothed spectra of $\mathrm{BOH}$ and $\mathrm{MOH}$ in water $(\mathrm{pH}$ 13.0) with direct excitation of the anion form 
$\left(\lambda_{\mathrm{ex}}=445 \mathrm{~nm}\right)$. Using the published method described in ref. 38, the $\mathrm{pKa}^{*}$ values for $\mathrm{BOH}$ and $\mathrm{MOH}$ in water are estimated to be -2.3 and -2.4 from the above parameters of $\left[\mathrm{pKa}=5.8, \lambda_{\mathrm{a}}=(378 \mathrm{~nm}, 447\right.$ $\left.\mathrm{nm}), \lambda_{\mathrm{f}}=(458 \mathrm{~nm}, 548 \mathrm{~nm})\right]$ and $\left[\mathrm{pKa}=5.3, \lambda_{\mathrm{a}}=(380 \mathrm{~nm}, 446 \mathrm{~nm}), \lambda_{\mathrm{f}}=(464 \mathrm{~nm}, 553 \mathrm{~nm})\right]$, respectively.
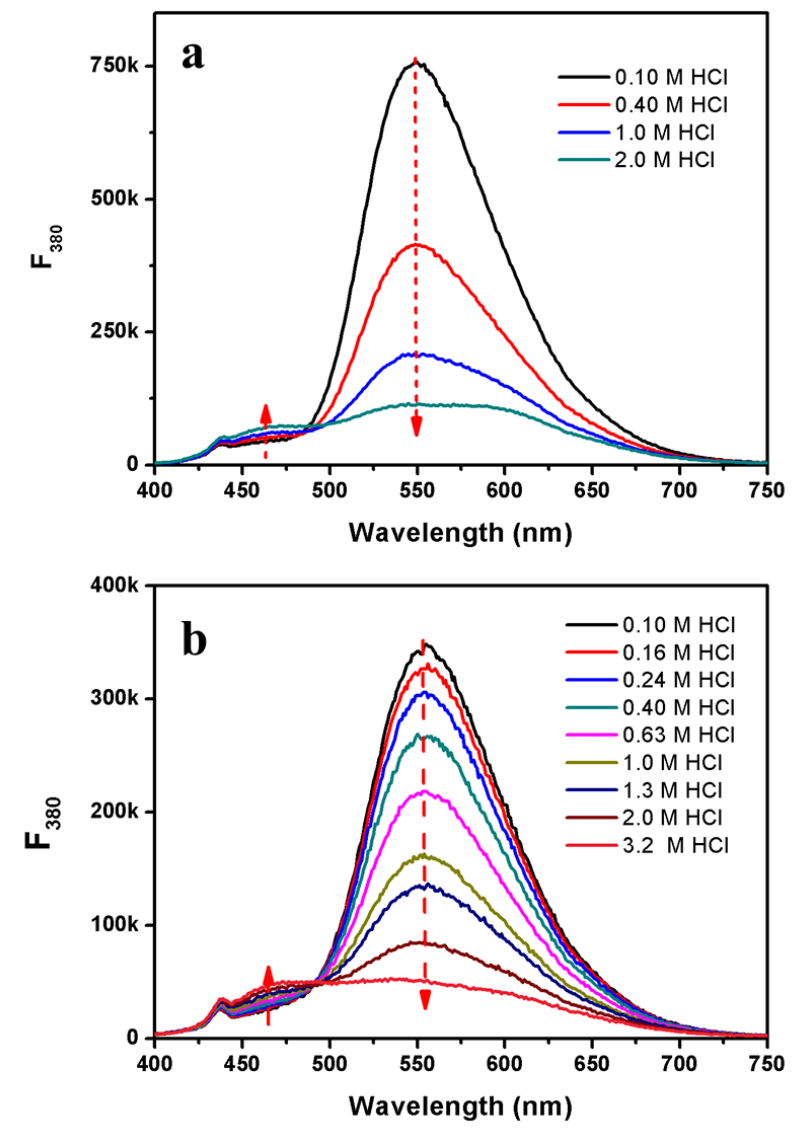

Fig. 5. Fluorescence spectra of (a) $\mathrm{BOH}(13 \mu \mathrm{M})$ and (b) $\mathrm{MOH}(5 \mu \mathrm{M})$ at various $\mathrm{pH}$ values in $\mathrm{HCl}$ aqueous solutions with $1 \%$ DMSO as a co-solvent, $\lambda_{e x}=380 \mathrm{~nm}$.

It is notable that a new fluorescence band peaked at $532 \mathrm{~nm}$ arises for $\mathrm{BOH}$ at $[\mathrm{HCl}]=7.9 \mathrm{M}$ and grows stronger in concentrated $\mathrm{HCl}(\sim 12 \mathrm{M})$ with $\Phi_{f}=0.097$ (Fig. 6a). A similar spectral evolution is observed for $\mathrm{MOH}$, with $\lambda_{e m}=544 \mathrm{~nm}$ and $\Phi_{f}=0.052$ in concentrated $\mathrm{HCl}$ (Fig. 6b). The fluorescence intensity at $550 \mathrm{~nm}$ with excitation at $380 \mathrm{~nm}$ is plotted against [ $\mathrm{HCl}]$ to clearly show the decrease of the band from $\mathrm{RO}^{-*}$ and the increase of the new one in the case of $\mathrm{MOH}$ (Fig. 6b, inset). The formation of the new fluorescence band is also observed for samples in $\mathrm{H}_{2} \mathrm{SO}_{4}$ aqueous solutions (Fig. S7). Compared with Fig. 6, the peaks of the new bands in $\mathrm{H}_{2} \mathrm{SO}_{4}$ aqueous solutions show a slight blue-shift, which is due to the difference of the solvent property. $\mathrm{BOH}$ and $\mathrm{MOH}$ should survive from acidic conditions at room temperature, because both compounds are synthesized in refluxed concentrated HI $(54 \%)[17,22]$ and the absorption spectra of $\mathrm{MOH}$ in $\mathrm{HCl}$ from $0.01 \mathrm{M}$ to $12 \mathrm{M}$ keep almost 
unchanged (Fig. S2b). Thus the new fluorescence bands in $\mathrm{HCl}$ should be attributed to some complexes.
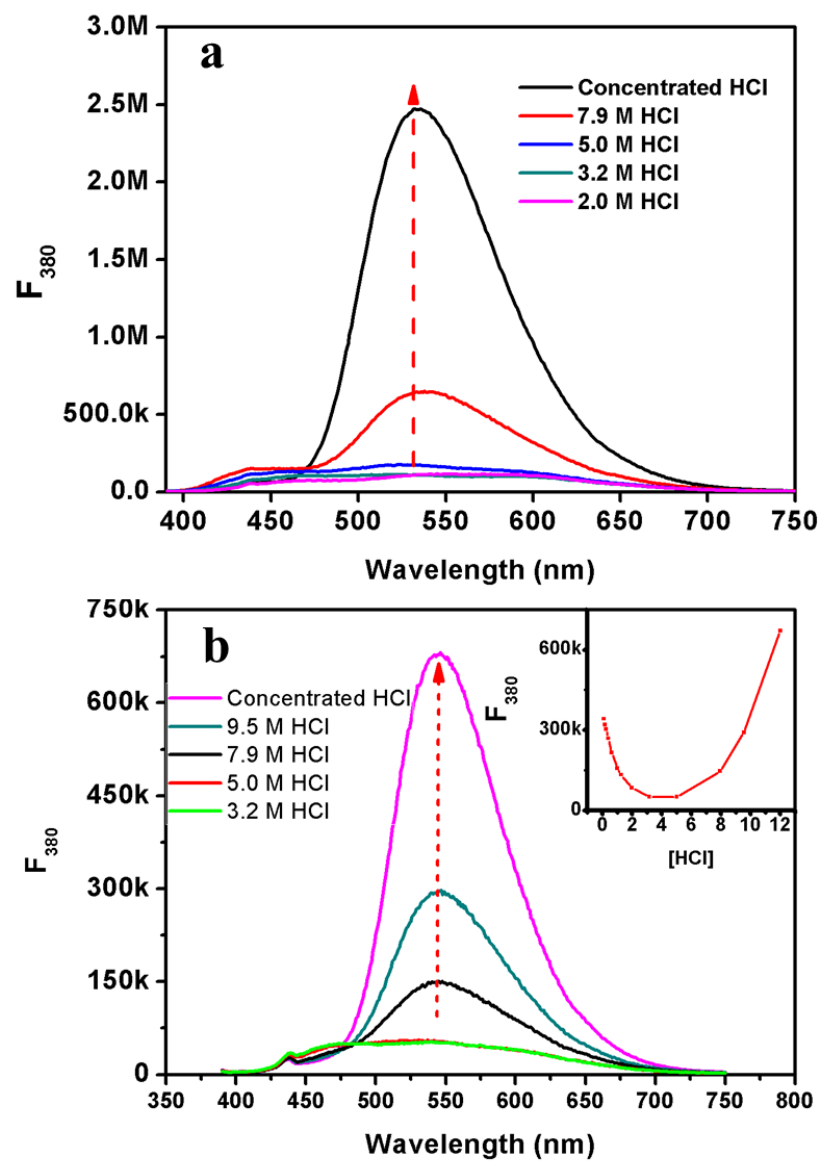

Fig. 6. The growth of new peaks in the fluorescence spectra of (a) BOH (13 $\mu \mathrm{M})$ and (b) $\mathrm{MOH}(5$ $\mu \mathrm{M})$ in $\mathrm{HCl}$ aqueous solutions (1\% DMSO as a co-solvent), $\lambda_{e x}=380 \mathrm{~nm}$. The inset shows the intensity at $550 \mathrm{~nm}$ for $\mathrm{MOH}$ with various concentrations of $\mathrm{HCl}$.

According to the Eigen-Weller model for proton transfer, CIP is an reaction intermediate $\left[\mathrm{RO}^{-*} * .\right.$. $\mathrm{H}^{+}$] consumed via diffusion controlled separation into a solvated proton (hydronium ion) and a solvated anionic form of the excited photoacid $[6,12,13]$. It may be difficult for CIP to get separated in such an environment as concentrated $\mathrm{HCl}$ with lesser availability of free water molecule. From another point of view, following the Eigen-Weller model and the equilibrium movement principle, the concentration of CIP should be considerable when the concentration of $\mathrm{H}^{+}$is substantial to recombine with $\mathrm{RO}^{-*}$. Thus we tend to believe that CIPs are the complexes that give the blue-shifted emission.

It should be noted that, in the study of the ESPT reactions of 5-cyano-2-naphthol in sub- and supercritical water, Kobayashi and coworkers found that the emission of their $\mathrm{ROH}^{*}$ or $\mathrm{RO}^{-*}$ was replaced by a band from an unknown $X^{*}$ [31]. They assigned the fluorescence of the unknown chemical species as CIP. In our case, the emission spectra shows the growth of a new peak rather than a 
shifting of the original peaks of $\mathrm{ROH}^{*}$ and $\mathrm{RO}^{-*}$, therefore it is plausible to assume that the emission band of $\mathrm{MOH}$ or $\mathrm{BOH}$ in concentrated $\mathrm{HCl}$ originates from the CIP resulted from the ESPT process.

CIP and the free base are usually undistinguishable in the steady-state fluorescence spectra [39]. To the best of our knowledge, a resolved single-peak-shaped curve has never been reported for CIP in the steady-state fluorescence spectrum under room temperature. As mentioned above in water at elevated temperature and pressure, the authors discovered a CIP band in the steady-state fluorescence spectrum; however, attempts of using theoretical calculations based on their model to simulate the CIP failed to gain direct evidence for the existence of CIP in the excited-state. As discussed below, we show theoretical calculations to investigate the $\mathrm{CIP}$ in the $\mathrm{BOH}$ system.

It is reported that the transformation of the ESPT from a photoacid to water is effectively controlled by the size of the water cluster and " 4 " is a key number regarding the number of water molecules accepting the proton [ 40, 41]. As shown in Fig. 7, to model the CIP, 4 water molecules are connected to the proton donor group of $\mathrm{BOH}$ so that the structure of the hydrated proton is similar to that of the Eigen cation $\left(\mathrm{H}_{9} \mathrm{O}_{4}^{+}\right)$, where a $\mathrm{H}_{3} \mathrm{O}^{+}$core is symmetrically surrounded by 3 water molecules in room-temperature aqueous acidic solutions [42]; the butyl group is simplified as methyl to reduce computational costs. Also, since hydrogen bonding may play an important role in regulating the fluorescence property of a dye [43-47], the hydrogen bonding interactions between water molecules and the carbonyl groups of $\mathrm{BOH}\left(\mathrm{B}_{1}\right.$ and $\left.\mathrm{B}_{2}\right)$ are considered and ignored in model $\mathrm{A}$ and $\mathrm{B}$, respectively, to investigate the effect on the calculation results. Based on the optimized structures, the model A is calculated to absorb at $\lambda_{a}=384 \mathrm{~nm}\left(\mathrm{f}=0.2683\right.$ ) and emit at $\lambda_{f}=518 \mathrm{~nm}$ ( $\left.\mathrm{f}=0.2662\right)$; the agreement between the theoretical and experimental results $\left(\lambda_{a}=383 \mathrm{~nm}, \lambda_{f}=532 \mathrm{~nm}\right)$ is reasonable. For model B, the calculated photophysical properties $\left(\lambda_{a}=377 \mathrm{~nm}, \mathrm{f}=0.2541 ; \lambda_{f}=515 \mathrm{~nm}, \mathrm{f}=0.2503\right)$ are nearly as impressive as above. 

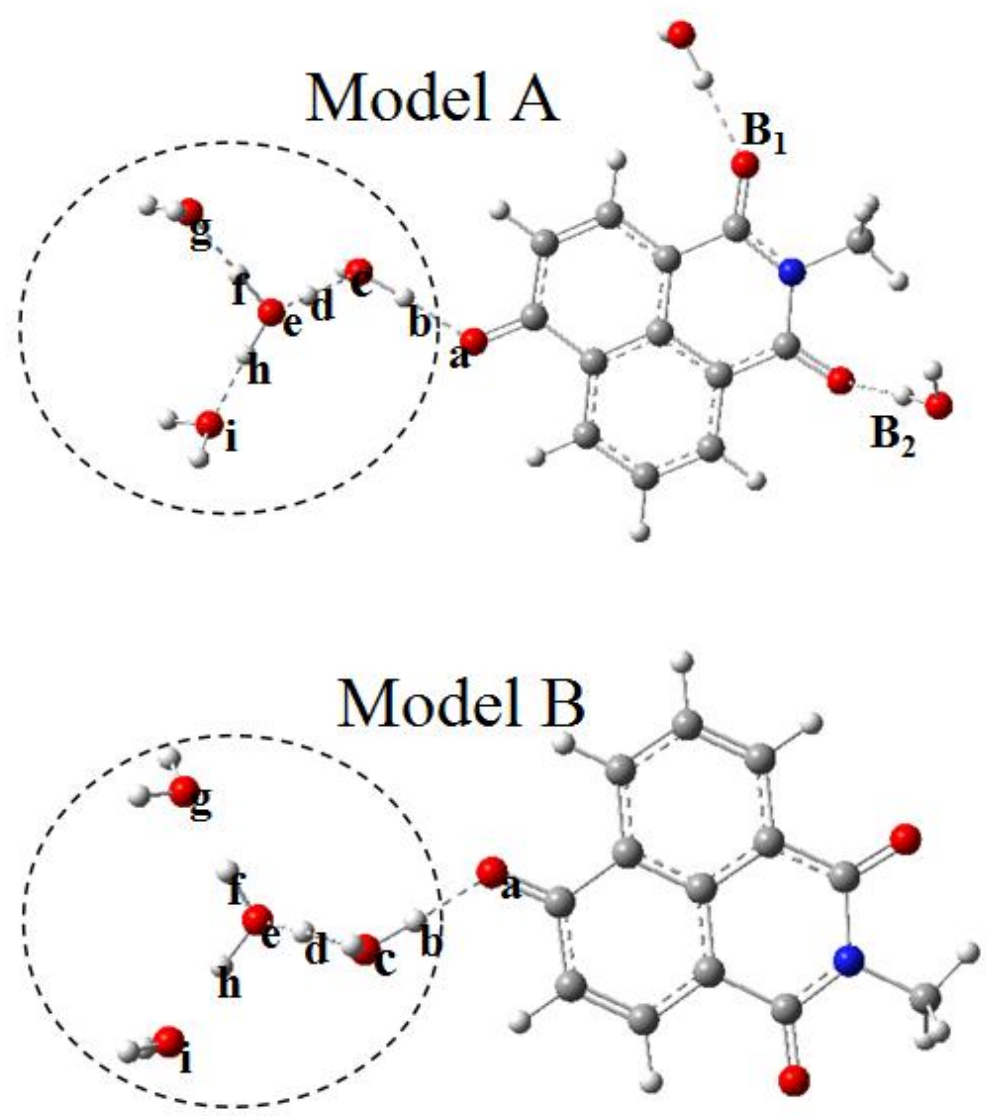

Fig. 7. Proposed structures of the CIP models for BOH.

The TDDFT method has proven useful to theoretically investigate the hydrogen bonding interactions that occur in the excited-state [40,43]. As shown in Table 3, for model A, from the optimized structure of the $S_{0}$ state to that of the $S_{1}$ state, the bond length of $\mathrm{O}_{\mathrm{a}}-\mathrm{H}_{\mathrm{b}}$ increases from 1.01 $\AA$ to $1.59 \AA$, and concomitantly the bond length of $\mathrm{O}_{\mathrm{c}}-\mathrm{H}_{\mathrm{b}}$ is shortened by $0.60 \AA$; these structural changes show the proton ejection and acceptance processes; $\mathrm{B}_{1}$ and $\mathrm{B}_{2}$ are weak both in the $\mathrm{S}_{0}$ and $\mathrm{S}_{1}$ states and therefore proton transfer reactions is not likely to happen in these sites. For model B without the presence of water molecules near the carbonyl groups, the ESPT process is also indicated with the length of $\mathrm{O}_{\mathrm{a}}-\mathrm{H}_{\mathrm{b}}$ increased by $0.58 \AA$ and $\mathrm{O}_{\mathrm{c}}-\mathrm{H}_{\mathrm{b}}$ shortened by $0.62 \AA$.

Table 3

Bond lengths of the optimized structures of the CIP models depicted in Fig. 7. 


\begin{tabular}{|c|c|c|c|c|c|c|c|c|c|c|c|}
\hline & & $\mathrm{O}_{\mathrm{a}}-\mathrm{H}_{\mathrm{b}}$ & $\mathrm{O}_{c}-\mathrm{H}_{\mathrm{b}}$ & $\mathrm{O}_{\mathrm{c}}-\mathrm{H}_{\mathrm{d}}$ & $\mathrm{O}_{\mathrm{e}}-\mathrm{H}_{\mathrm{d}}$ & $\mathrm{O}_{\mathrm{e}}-\mathrm{H}_{\mathrm{f}}$ & $\mathrm{O}_{\mathrm{g}}-\mathrm{H}_{\mathrm{f}}$ & $\mathrm{O}_{\mathrm{e}}-\mathrm{H}_{\mathrm{h}}$ & $\mathrm{O}_{i}-\mathrm{H}_{\mathrm{h}}$ & $\mathrm{B}_{1}$ & $\mathrm{~B}_{2}$ \\
\hline \multirow{2}{*}{ A } & $\mathbf{S}_{0}$ & 1.01 & 1.61 & 1.00 & 1.67 & 0.98 & 1.82 & 0.98 & 1.82 & 1.87 & 1.86 \\
\hline & $\mathrm{S}_{1}$ & 1.59 & 1.01 & 1.40 & 1.07 & 1.01 & 1.59 & 1.01 & 1.59 & 1.84 & 1.80 \\
\hline \multirow{2}{*}{ B } & $\mathbf{S}_{0}$ & 1.00 & 1.63 & 1.00 & 1.67 & 0.98 & 1.82 & 0.98 & 1.82 & - & - \\
\hline & $S_{1}$ & 1.58 & 1.01 & 1.40 & 1.07 & 1.01 & 1.59 & 1.01 & 1.59 & - & - \\
\hline
\end{tabular}

Furthermore, the ESPT reaction is followed by TDDFT to provide a quantitative description of the potential energy curve, which is explored using relaxed potential energy scan that constrains the proton transfer coordinate (the $\mathrm{Oa}-\mathrm{H}_{\mathrm{b}}$ bond length) and minimizes all the other coordinates at every scan point (Fig. 8). The activation barrier for the ESPT reaction is only $3.2 \mathrm{kcal} / \mathrm{mol}$ and $3.8 \mathrm{kcal} / \mathrm{mol}$ for model A and $\mathrm{B}$ respectively, which predicts that at room temperature the reaction should occur easily after photon absorption. It is reported that hydrogen-bonding can facilitate excited-state intramolecular proton transfer (ESIPT) [48]; our results indicate that the hydrogen bonding interaction may make the intermolecular ESPT reaction easier to happen. Moreover, by scanning the potential curve, we also notice that there are two stable structures for each model in the $S_{1}$ state. For model $A$, beside the structure discussed above, the other stable structure in in the $\mathrm{S}_{1}$ state that corresponding to the $\mathrm{O}_{\mathrm{a}}-\mathrm{H}_{\mathrm{b}}$ bond length of $1.03 \AA$ is also obtained and gives an calculated emission peak of $450 \mathrm{~nm}$ ( $f=0.3172$ ), which corresponds to the neutral form of $\mathrm{BOH}$ in water.
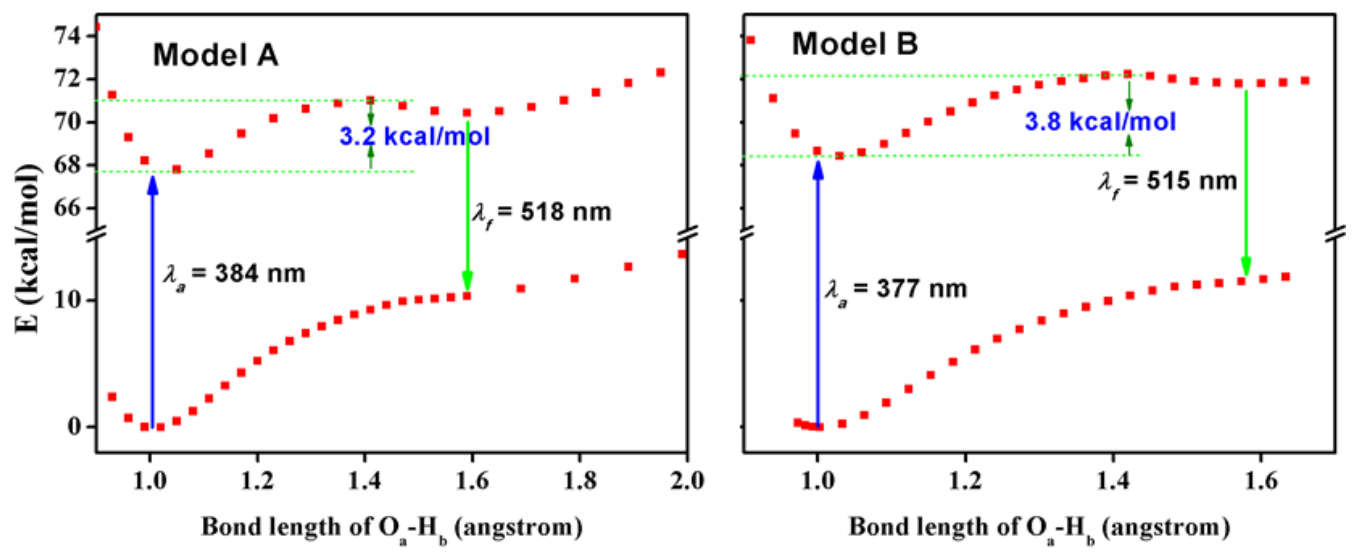

Fig. 8. Optimized energy profiles for $\mathrm{S}_{1}$ and $\mathrm{S}_{0}$ of model $\mathrm{A}$ and $\mathrm{B}$ along the phenolic $\mathrm{O}_{\mathrm{a}}-\mathrm{H}_{\mathrm{b}}$ bond as obtained at the B3LYP/TZVP calculation level.

\section{Conclusion}

In this work, we have presented the steady-state absorption and emission spectra of two 4-hydroxyl-1, 8-naphthalimide derivatives (BOH and $\mathrm{MOH}$ ) in various organic solvents and aqueous solutions. It is shown that both compounds undergo ESPT reactions in methanol, DMSO and water. The different emission data between the two compounds are explained theoretically by the DFT/ TDDFT methods. In aqueous solution, both compounds can be used as ratiometric $\mathrm{pH}$ probes, and meantime they show strong photoacidity with negative $\mathrm{pKa}^{*}$ values. 
Nevertheless, an unexpected single-peak-shaped band is observed in the steady-state fluorescence spectra of $\mathrm{MOH}$ or $\mathrm{BOH}$ in concentrated $\mathrm{HCl}$ at room temperature, which has not been reported in the study of photoacids before; we also envision theoretically that this band originates from the CIP formed by the anionic form of the photoacid and the hydrated proton. These results have given valuable information about the structure and stability of the CIP in the Eigen-Weller model.

\section{Acknowledgements}

We are grateful to the National Science Foundation of China (no.XXXXXX) for financial support.

\section{Electronic supplementary information (ESI)}

Electronic supplementary information (ESI) available: Additional absorption spectra of $\mathrm{BOH}$ and $\mathrm{MOH}$, Cartesian coordinates for the optimized geometries. See DOI:

\section{Notes and references}

(1) T. Förster, Naturwissenschaften 36 (1949) 186.

(2) B. van, Oort, M. J. T. ter Veer, M. L. Groot, I. H. M. van Stokkum, Phys. Chem. Chem. Phys. 14 (2012) 8852 .

(3) S. Chai, G. Zhao, P. Song, S. Yang, J. Liu, K. Han, Phys. Chem. Chem. Phys. 11 (2009) 4385.

(4) D. J. Stewart, J. J. Concepcion, M. K. Brennaman, R. A. Binstead, T. J. Meyer, Natl. Acad. Sci. U. S. A. 110 (2013) 876.

(5) J. Ma, X. Zhang, N. Basaric, P. Wan, D. L. Phillips, Phys. Chem. Chem. Phys. 17 (2015) 9205.

(6) T. Kumpulainen, B. H. Bakker, M. Hilbers, A. M. Brouwer, J. Phys. Chem. B 119 (2015) 2515.

(7) A. Brenlla, M. V. Gutié rrez, M. C. R. Rodríguez, F. Rodríguez-Prieto, M. Mosquera, J. L. P. Lustres, J. Phys. Chem. Lett. 5 (2014) 989.

(8) M. Savarese, P. A. Netti, N. Rega, C. Adamo, I. Ciofini, Phys. Chem. Chem. Phys. 16 (2014) 8661.

(9) A. Douhal, F. Lahmani, A. H. Zewail, Chem. Phys. 207 (1996) 477.

(10) L. M. Tolbert, K. M. Solntsev, Acc. Chem. Res. 35 (2002) 19.

(11) N. Agmon, J. Phys. Chem. A 109 (2005) 13.

(12) A. Weller, Prog. React. Kinet. 1 (1961) 187.

(13) M. Eigen, W. Kruse, G. Maass, L. de Maeyer, Prog. React. Kinet. 2 (1964) 285.

(14) T. Kumpulainen, B. H. Bakker, A. M. Brouwer, Phys. Chem. Chem. Phys. 17 (2015) 20715

(15) Y, Kai, Y. Hu, K. Wang, W. Zhi, M. Liang, Yang, W. Spectrochim. Acta, Part A, 118 (2014) 239.

(16) B. Zhu, B. Guo, Y. Zhao, B. Zhang, B. Du. Biosens. and Bioelectron. 55 (2014) 72.

(17) J. Ren, Z. Wu, Y. Zhou, Y. Li, Z. Xu. Dyes Pigm. 91 (2011) 442.

(18) T. Liu, X. Zhang, Q. Qiao, C. Zou, L. Feng, J. Cui, Z. Xu. Dyes Pigm. 99 (2013) 537.

(19) J. Shi, Y. Wang, X. Tang, W. Liu, H. Jiang, W. Dou, W. Liu. Dyes Pigm. 100 (2014) 255.

(20) H. Jiang, J. Jiang, J. Cheng, W. Dou, X. Tang, L. Yang, W. Liu, D. Bai. New J. Chem. 38 (2014) 109. 
(21) C. Liu, H. Wu, Z. Wang, C. Shao, B. Zhu, X. Zhang. Chem. Commun. 50 (2014) 6013.

(22) T. Liu, Z. Xu, D. R. Spring, J. Cu. Org. Lett. 15 (2013) 2310.

(23) B. Zhu, C. Gao, Y. Zhao, C. Liu, Y. Li, Q. Wei, Z. Ma, B. Du, X. Zhang, Chem. Commun. 47 (2011) 8656.

(24) X. Lv, G. Ge, L. Feng, J. Troberg, L. Hu, J. Hou, H. Cheng, P. Wang, Z. Liu, M. Finel, J. Cui, Ling Yang. Biosens. and Bioelectron. 72 (2015) 261.

(25) Y. Sun, D. Zhao, S. Fan, L. Duan. Sens. Actuators, B 208 (2015) 512.

(26) C. Liu, C. Shao, H. Wu, B. Guo, B. Zhu, X. Zhang, RSC Adv., 4 (2014) 16055.

(27) B. Zhu, H. Jiang, B. Guo, C. Shao, H. Wua, B. Du, Q. Wei. Sens. Actuators, B 186 (2013) 681.

(28) M. Xu, J. Han, Y. Zhang, X. Yang, L. Zang. Chem. Commun. 49 (2013) 11779.

(29) Y. Wen, K. Liu, H. Yang, Y. Li, H. Lan, Y. Liu, X. Zhang, T. Yi. Anal. Chem. 86 (2014) 9970.

(30) L. Biczók, P. Valat, V. Wintgens, Phys. Chem. Chem. Phys. 1 (1999) 4759.

(31) I. Kobayashi, M. Terazima , Y. Kimura, J. Phys. Chem. B 116 (2012) 1043.

(32) M. J. Frisch, G. W. Trucks, H. B. Schlegel, G. E. Scuseria, M. A. Robb, J. R. Cheeseman, G. Scalmani, V. Barone, B. Mennucci, G. A. Petersson, H. Nakatsuji, M. Caricato, X. Li, H. P. Hratchian, A. F. Izmaylov, J. Bloino, G. Zheng, J. L. Sonnenberg, M. Hada, M. Ehara, K. Toyota, R. Fukuda, J. Hasegawa, M. Ishida, T. Nakajima, Y. Honda, O. Kitao, H. Nakai, T. Vreven, J. A. Montgomery, Jr. J. E. Peralta, F. Ogliaro, M. Bearpark, J. J. Heyd, E. Brothers, K. N. Kudin, V. N. Staroverov, T. Keith, R. Kobayashi, J. Normand, K. Raghavachari, A. Rendell, J. C. Burant, S. S. Iyengar, J. Tomasi, M. Cossi, N. Rega, J. M. Millam, M. Klene, J. E. Knox, J. B. Cross, V. Bakken, C. Adamo, J. Jaramillo, R. Gomperts, R. E. Stratmann, O. Yazyev, A. J. Austin, R. Cammi, C. Pomelli, J. W. Ochterski, R. L. Martin, K. Morokuma, V. G. Zakrzewski, G. A. Voth, P. Salvador, J. J. Dannenberg, S. Dapprich, A. D. Daniels, O. Farkas, J. B. Foresman, J. V. Ortiz, J. Cioslowski, D. J. Fox, Gaussian, Inc. Wallingford CT, 2010.

(33) A. D. Becke, J. Chem. Phys. 98 (1993) 5648.

(34) O. Treutler, R. Ahlrichs, J. Chem. Phys. 102 (1995) 346.

(35) R. F. Chen, Anal. chem. 19 (1967) 374.

(36) M. S. Alexiou, V. Tychopoulos, S. Ghorbanian, J. H. P. Tyman, R. G. Brown, P. I. J. Brittain, Chem. Soc. PERKIN TRANS. 2 (1990) 837.

(37) J. Han, K. Burgess, Chem. Rev. 110 (2010) 2709.

(38) B. Marciniak, H. Kozubek, S. Paszyc, J. Chem. Educ. 69 (1992) 247.

(39) J. S. Seixas de Melo, A. L. Maçanita, J. Phys. Chem. B 119 (2015) 2604.

(40) Y. Liu, T. Chu, Chem. Phys. Lett. 505 (2011) 117.

(41) E. Bardez, A. Fedorov, M. N. Berberan-Santos, J. M. G. Martinho, J. Phys. Chem. A 103 (1999) 4131 .

(42) M. Eigen, Angew. Chem. Int. Ed. 3 (1964) 1.

(43) G. Zhao, J. Liu, L. Zhou, K. Han, J. Phys. Chem. B 111 (2007) 8940.

(44) G. Zhao, K. Han, Acc. Chem. Res. 45 (2012) 404. 
(45) G. Zhao, K. Han, Biophys. J. 94 (2008) 38.

(46) J. Zhao, P. Song, F. Ma, Commun. Comput. Chem. 2 (2014) 117.

(47) L. Liu, D. Yang, Commun. Comput. Chem. 2 (2014) 108.

(48) C. Li, C. Ma, D. Li, Y. Liu, J. Lumin. 172 (2016) 29. 